\title{
COMPARATIVE STUDIES ON THE EFFECT OF CHLORPROMAZINE AND IMIPRAMINE FROM A VIEWPOINT OF PHYLOGENY
}

\author{
Nobuko HorikiRI AND Hideomi TugE \\ Biological and Physiological Laboratory, Hosei University
}

Since the discovery of chlorpromazine as a splendid depressant drug, a great number of neurophysiological as well as neuropharmacological investigations on different kinds of animals with chlorpromazine have been conducted and a great deal of informations accumulated. Imipramine as an effective anti-depressant drug, the literature of which though less abundant, has also been treated in order to solve the mechanism of action on the central nervous system as a subject of neurophysiology. As is well known, chlorpromazine and imipramine having a very similar chemical structure react differently, the former behaves as depressant while the latter as anti-depressant. Although this problem is of utmost interest, up to the present, the mechanism involved to explain the difference of the two drugs remains unsolved.

Nevertheless, based upon the EEG study soon after the exploitation of chlorpromazine, hypotheses are presented that chlorpromazine acts selectively upon the brain stem reticular formations in different ways (HIEBEL et al., 1954 ; Longo et al., 1954; ANOKHIN, 1956; BRAdLey \& Key, 1958; Longo, 1962). It is also suggested by some authors, though not much conclusive, that imipramine gives a complicated effect through the reticular formations (VAN Meter et al., 1959; Himwich, 1959).

In our present study an approach was made to obtain certain information about the mechanism of action of the two drugs on the central nervous system, particularly on the reticular formations from the point of view of phylogeny. As far as we are aware of, only a few works which studied systematically on this line have been published. The comparative study of chlorpromazine made by BARUK et al. (1955) and IVANOvA's (1961) work dealing with chlorpromazine on the conditioned reflexes were instructive. In the present experiment, using certain kinds of representative animals in evolution, from fish to rabbits, the effect of chlorpromazine and imipramine on the overt behavior, EEG and conditioned reflex activity were observed.

Received for publication March 1, 1969

堀切叙子, 柘植秀臣 


\section{MATERIALS AND METHODS}

To investigate the effects of chlorpromazine and imipramine of different doses on the overt behavior, fishes (carp, crucians and red killifishes), frogs, pigeons, mice, rats and rabbits were used. Chlorpromazine $(\mathrm{CPZ})$ under the trade name wintermin produced by Shionogi Pharmacy Co. Ltd. and imipramine (IMP) under the trade name tofranil produced by Fujisawa Drugs Industry Co. Ltd. were used.

For the observations on the effects of $\mathrm{CPZ}$ and IMP on the electroencephalogram (EEG) and electrocardiogram (ECG), pigeons and rabbits were used by applying the sound stimulus, that is, the metronome (MT). Further, in order to observe the effects of the drugs on the conditioned reflex $(\mathrm{CR})$, the drugs were administered after the stabilization of the defensive motor conditioned reflex (DCR) in pigeon, and, of the food motor conditioned reflex (FCR) both in pigeon and rabbit.

For the elaboration of DCR, the pigeon was confined onto soft towels supported by a rack. Then, while recording EEG and ECG, a sound of $1000 \mathrm{c} / \mathrm{s}$ for 5 seconds with intervals at random was used as a conditioned stimulus (CS), and 1 second after the introduction of CS an electric current was given to the left leg as an unconditioned stimulus (US). In the case of FCR in the pigeon, while recording EEG, a light of 20 $\mathrm{W}$ was given for 15 seconds as CS, and if the pigeon pecked at a key during the given time, foods were reinforced. With rabbit, the same method and procedures for the pigeon were applied except a bar for pressing was used instead of the key.

Three leading electrodes of silver wire for EEG were implanted strictly onto the dura and fixed with dental resin to the skull, one on the frontal area and the other two on the occipital of the cortex. A silver cord of $3 \mathrm{~cm}$ with a diameter of $0.3 \mathrm{~mm}$ was implanted in the muscle at the back of the neck and a needle was inserted in the left thigh to serve as the leading electrodes for ECG.

\section{RESULTS}

\section{Observation on the behavioral changes.}

In carp and crucians, CPZ and IMP of doses of 5,25 and $125 \mathrm{mg} / \mathrm{kg}$ of the body weight were used respectively. With an injection of $5 \mathrm{mg} / \mathrm{kg}$ of $\mathrm{CPZ}$, a gentle up-and-down movement in an upright position and the 'rising up to the surface' movement were observed. An increase in the doses of $\mathrm{CPZ}$ up to $125 \mathrm{mg} / \mathrm{kg}$ witnessed the retreating movement of the fish and its recovery required a long time.

With $5 \mathrm{mg} / \mathrm{kg}$ of IMP the bodily balance was impaired, movement of the fins was unusually active and a retreating movement accompanied with the up-and-down movement in an upright position could be observed remarkably. In addition with $25 \mathrm{mg} / \mathrm{kg}$ and $125 \mathrm{mg} / \mathrm{kg}$, upright position with the dorsal touching the side of the aquarium could be observed.

In the case of the red killifish, instead of injection it is placed in the dish containing the solution of $\mathrm{CPZ}$ or IMP in water in the following ratios per litre: (a) $12.5 \mathrm{mg}$; (b) $6.3 \mathrm{mg}$; (c) $3.1 \mathrm{mg}$; (d) $1.6 \mathrm{mg}$; (e) $0.8 \mathrm{mg}$; (f) $0.4 \mathrm{mg}$; (g) $0.2 \mathrm{mg}$. For convenience, alphabets are used to represent respectively the solutions in the ratios as stated above. The following effects and results 
were obtained. Solution of CPZ. All fishes in solutions (a) and (b) died within one hour. Fishes in solutions (c) and (d) died within 24 hours. Fishes in solution (e) sometimes lay on their side at the bottom of the dish while those in solution ( $f$ ) and in solutions containing the drug less than as in ( $f$ ) showed no effect at all. Solutions of IMP. All the fishes in solution (a) died within 80 minutes, whereas that in solution (b) within 24 hours and those in solution (c) within 48 hours. The fishes in solution (d) lay on their side at the bottom of the dish, whereas those in solution (e) and solutions containing the drug less than as in solution (e) showed no effect at all. The result obtained demonstrates that IMP acts upon fishes more strongly than CPZ except in cases of the permeation experiment in the red killifish. In this series of experiment, it is interesting to note that fishes released into the solution of drugs appear to be affected more profoundly and quickly due to the permeation of the drugs through the gill raker than by injection.

56 frogs were used to observe the effects of CPZ and IMP of doses of 5 , $25,50,75,100$ and $125 \mathrm{mg} / \mathrm{kg}$. No effects were observed with the injection of doses less than $50 \mathrm{mg} / \mathrm{kg}$ of $\mathrm{CPZ}$. 8 frogs injected with $75 \mathrm{mg} / \mathrm{kg}$ of $\mathrm{CPZ}$ each showed an overt behavioral change, that is, flaccidity. Of the 8 frogs, 6 recovered and 2 died. Half of the animals, each injected with doses of 100 络 or $125 \mathrm{mg} / \mathrm{kg}$ of $\mathrm{CPZ}$ died.

With the injection of $25 \mathrm{mg} / \mathrm{kg}$ of IMP flaccidity was observed while all those injected with doses over $50 \mathrm{mg} / \mathrm{kg}$ died.

In pigeons, doses of 5,25 and $125 \mathrm{mg} / \mathrm{kg}$ of $\mathrm{CPZ}$, and $1,5,25$ and 125 $\mathrm{mg} / \mathrm{kg}$ of IMP were used. The drugs were administered into the muscle of the breast. Only a little flaccidity was observed with the administration of $25 \mathrm{mg} / \mathrm{kg}$ of $\mathrm{CPZ}$, but with the higher dose $(125 \mathrm{mg} / \mathrm{kg})$ striking flaccidity, vomiting and inflation of the crop continued for 24 hours.

In the case of $5 \mathrm{mg} / \mathrm{kg}$ of IMP, an alert state and frequent violent movements were produced. With increased doses, the pigeons became more excited and so were their behaviors such as vomiting, inflation of the crop and a remarkable disappearance of the orienting reflexes. The administration of $125 \mathrm{mg} / \mathrm{kg}$ of IMP caused a pronounced tetanus especially of the neck and an unbalance of the body. Many days were required for the recovery. When the successive injections of $1 \mathrm{mg} / \mathrm{kg}$ of IMP were applied at intervals of 15 to 20 minutes, the first injection did not cause any effect on the animal, but after the third injection remarkable vomiting was elicited.

In mice, intraperitoneal injection of CPZ and IMP of doses of 5, 25 and $125 \mathrm{mg} / \mathrm{kg}$ were applied respectively. An administration of $5 \mathrm{mg} / \mathrm{kg}$ of $\mathrm{CPZ}$ caused a slight flaccidity and decrease of the spontaneous movements. With $25 \mathrm{mg} / \mathrm{kg}$ of $\mathrm{CPZ}$ flaccidity and stretching out of the legs appeared and the animal lay on its belly, though at times walking about in the cage. It was rather lethargic and inactive. With $125 \mathrm{mg} / \mathrm{kg}$ of $\mathrm{CPZ}$ flaccidity and stretch- 
ing out of its legs were further aggravated.

With an injection of $5 \mathrm{mg} / \mathrm{kg}$ of IMP no behavioral changes were observed in mice. With $25 \mathrm{mg} / \mathrm{kg}$ of IMP the behavior became inactive while 125 $\mathrm{mg} / \mathrm{kg}$ of IMP caused a difficulty in walking and a dorsal bending posture continued with spasms occurring at times.

In rats intraperitoneal injections of $\mathrm{CPZ}$ and IMP of doses of 5, 25, 50 and $100 \mathrm{mg} / \mathrm{kg}$ were used respectively. $5 \mathrm{mg} / \mathrm{kg}$ of $\mathrm{CPZ}$ caused a slight flaccidity, but with an increase in the doses of $\mathrm{CPZ}$, remarkable flaccidity, quietness, streching of the legs and lying on its belly phenomena were observed. Recovery required some 24 hours.

With IMP in rats, no effects were observable even after an administration of a dose of $100 \mathrm{mg} / \mathrm{kg}$.

In rabbits, intraperitoneal injection of $\mathrm{CPZ}$ and IMP of doses of 2 and 5 $\mathrm{mg} / \mathrm{kg}$ were used. The $2 \mathrm{mg} / \mathrm{kg}$ of $\mathrm{CPZ}$ caused the rabbit to be quiet for a long time, though sometimes it moved spontaneously in the cage. With the passing of time, the rabbit lay on its belly but without showing any sign of flaccidity in its neck and legs. About 4 hours after injection the behavior of the animal appeared to return to normal. With the injection of $5 \mathrm{mg} / \mathrm{kg}$, at first tranquility was observed; and with the passing of time, it lay on its side with the flaccidity of its neck. Spontaneous movements did not appear even after some 3 hours. Its complete recovery was observed after 24 hours.

With an injection of $2 \mathrm{mg} / \mathrm{kg}$ of IMP, the animal was flaccid slightly, and with the passing of time sometimes lay on its belly quietly, but some 50 minutes after it appeared to recover from the effect of the drug. With 5 $\mathrm{mg} / \mathrm{kg}$ of IMP, body flaccidity and lying on its belly were observed for some 60 minutes and after this spontaneous activities resumed. At any rate, the sedative effect of both $\mathrm{CPZ}$ and IMP were obvious in rabbits.

2. Effects of the drugs on EEG and ECG.

Observations on the effects of the two drugs on EEG were made in pigeons and rabbits. Besides ECG was registered in pigeons. EEG and ECG were recorded before and after administration of the drugs.

In pigeons, with an administration of $5 \mathrm{mg} / \mathrm{kg}$ of $\mathrm{CPZ}$, a slight tendency of a slowing of frequency and high-voltage waves appeared and at the same time its pulse rate somewhat decreased. Some 15 minutes after injection, a slight activation on the EEG and some increases in its pulse rate in response to MT-stimulation were recorded (FIG. 1). The same result was observed with the presentation of MT at 30 minutes as well as one hour after injection.

With an injection of $5 \mathrm{mg} / \mathrm{kg}$ of IMP, EEG in the pigeon showed a marked desynchronization; that is, low-voltage fast waves, but its pulse rate decreased. Some 15 minutes after injection, in response to MT-stimulation 


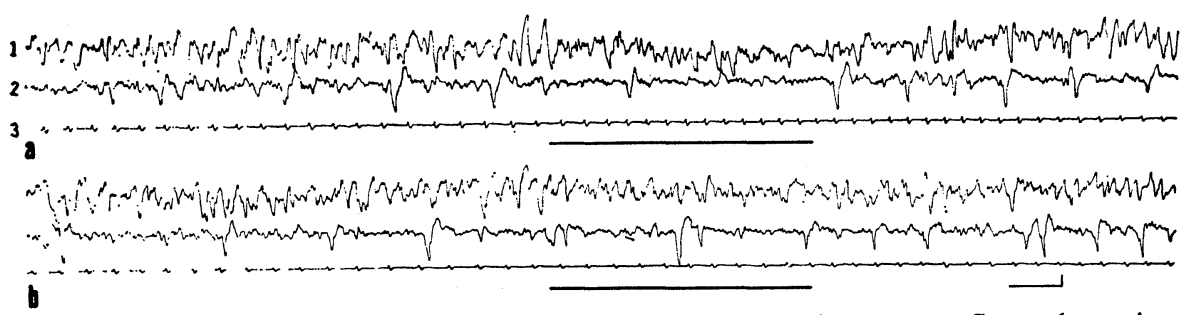

FIG. 1. Effect of $\mathrm{CPZ}$ on the EEG and ECG of the pigeon. a-Control tracing. $\mathrm{b}-15$ minutes after administration of $\mathrm{CPZ}(5 \mathrm{mg} / \mathrm{kg})$. Leads -1 : right frontal-right occipital area; 2: right occipital area; 3 : ECG. At the bar indifferent stimulation (metronome). Calibration : $100 \mu \mathrm{V}, 1$ sec.

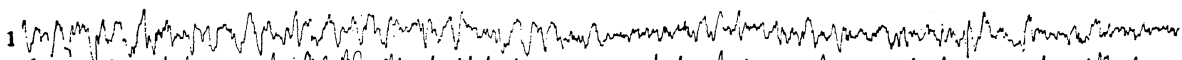

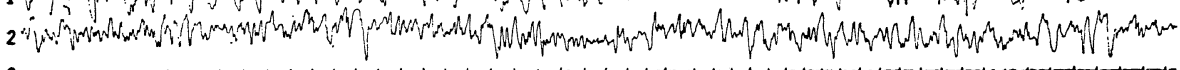
3

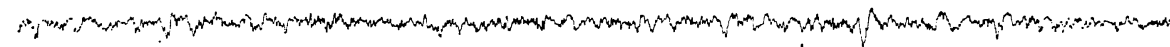
is

b

FIG. 2. Effect of IMP on the EEG and ECG of the pigeon. a-Control tracing. $\mathrm{b}-15$ minutes after administration of IMP $(5 \mathrm{mg} / \mathrm{kg})$. Leads and calibration as in FIG. 1.

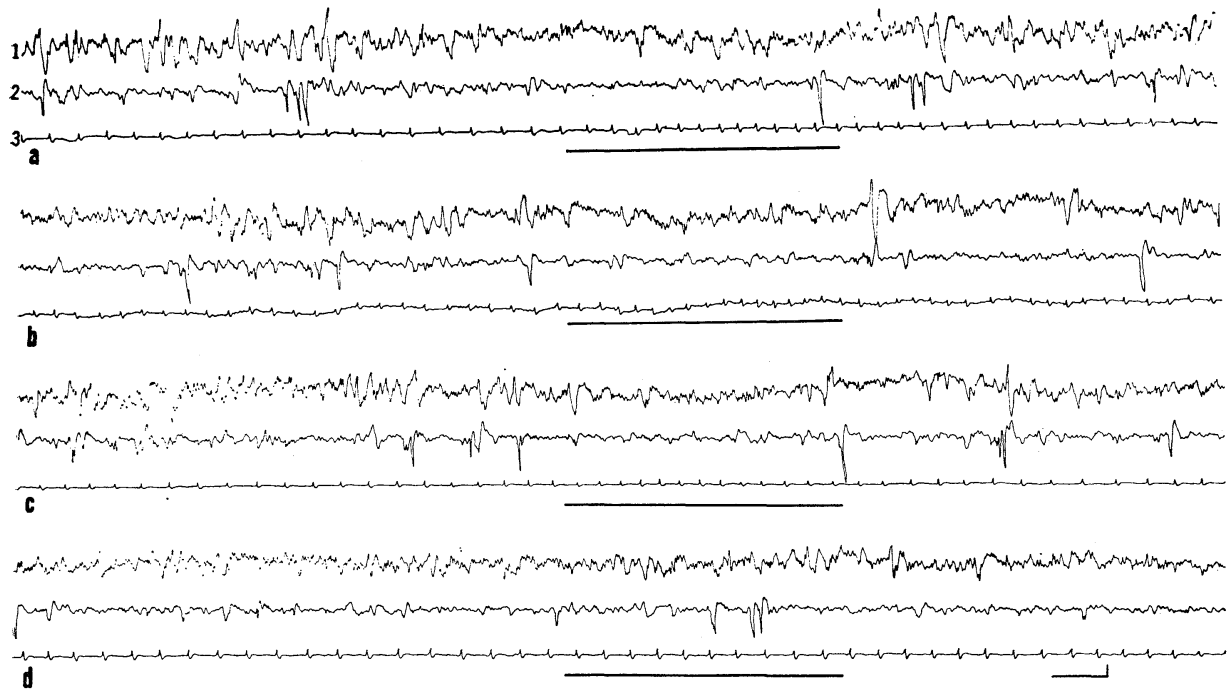

FIG. 3. Effect of increasing doses of IMP on the EEG and ECG of the pigeon. a-Control tracing. b-first trial: 15 minutes after administration of $1 \mathrm{mg} / \mathrm{kg}$. c-second trial : 15 minutes after administration of $1 \mathrm{mg} / \mathrm{kg}$. d-third trial: 15 minutes after administration of $1 \mathrm{mg} / \mathrm{kg}$. Leads and calibration as in FIG. 1 . 


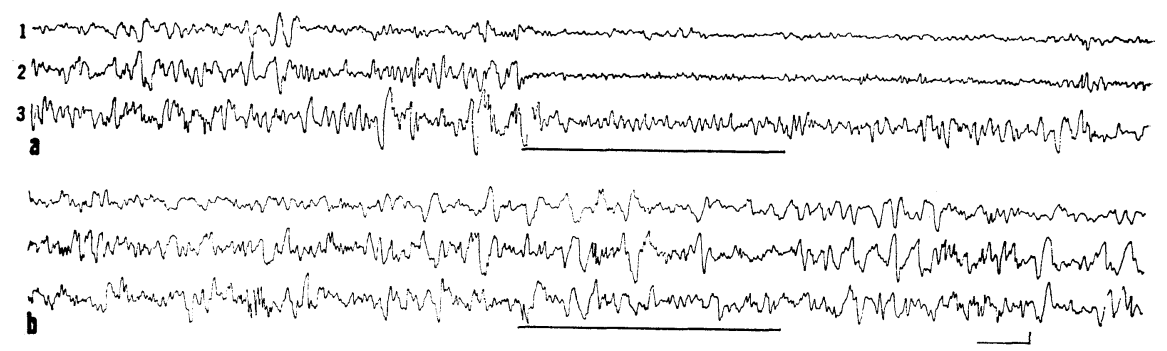

FIG. 4. Effect of $\mathrm{CPZ}$ on the EEG of the rabbit. a-Control tracing. b-About 20 minutes after administration of $\mathrm{CPZ}(5 \mathrm{mg} / \mathrm{kg})$. Leads -1 : right frontal area ; 2 : right occipital area; 3 : left parietal-left occipital area. At the bar indifferent stimulation (metronome). Calibration: $200 \mu \mathrm{V}, 1 \mathrm{sec}$.

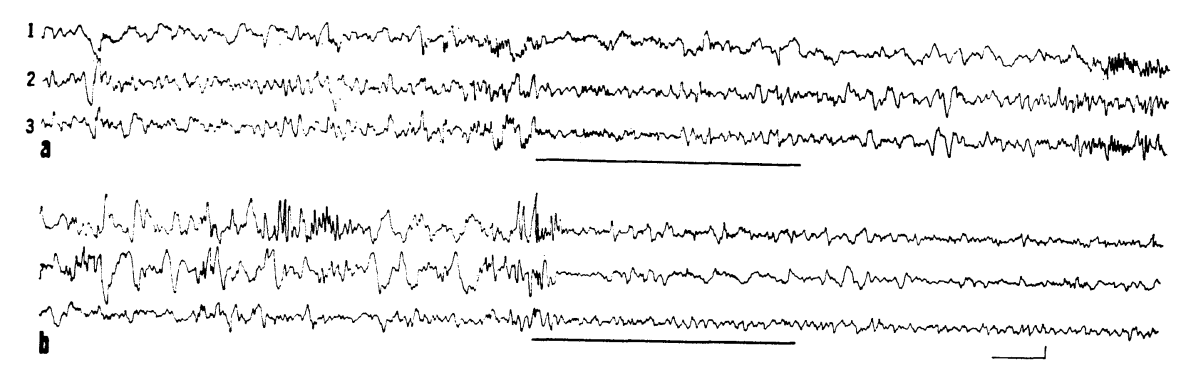

FIG. 5. Effect of IMP on the EEG of the rabbit. a-Control tracing. b-About 40 minutes after administration $(5 \mathrm{mg} / \mathrm{kg})$. Leads and calibration as in FIG. 4 .

no changes on EEG and ECG were observed (FIG. 2). The same result was recorded with the presentation of MT at 30 minutes as well as one hour after injection. The successive injection of $1 \mathrm{mg} / \mathrm{kg}$ of IMP at interval of some 15 to 20 minutes was made (FIG. 3). After the first injection of $1 \mathrm{mg}$ / $\mathrm{kg}$ of IMP the EEG in the pigeon showed no changes, but with the presentation of MT a pronounced activation on the EEG occurred (FIG. 3b). The same result was obtained with the second successive injection (FIG. 3c). After the third successive injection the EEG changed to low-voltage fast waves and heart beats tended to decrease as observed in the injection of $5 \mathrm{mg} / \mathrm{kg}$ of the same drug as stated above, and with the presentation of MT no changes on the EEG occurred (FIG. 3d). Therefore, the dose of $3 \mathrm{mg} / \mathrm{kg}$ may be the critical dosage in producing changes on EEG.

In rabbits, with the injection of $5 \mathrm{mg} / \mathrm{kg}$ of $\mathrm{CPZ}, \mathrm{EEG}$ changed from low to high-voltage waves and fast to slow frequency. Some 20 minutes later when MT was presented no changes on the EEG were observed (FIG. 4). With the presentation of MT, one hour after injection the same result was obtained. With the injection of $2 \mathrm{mg} / \mathrm{kg}$ of CPZ, EEG-tracings alternated between slow, high-voltage waves and fast, low-voltage waves; and the 
behavior of the animal alternated between wakefulness and drowsiness as well during the first several hours. EEG-tracings returned to normal about 4 hours after in jection.

With $5 \mathrm{mg} / \mathrm{kg}$ of IMP in rabbits, EEG changed from low to high-voltage waves and fast to slow frequency. About 10 minutes later MT was presented and EEG showed desynchronization differing with that of rabbits treated with CPZ. With the presentation of MT about 40 minutes after injection the same result was observed (FIG. 5). 10 minutes after injection of $2 \mathrm{mg} / \mathrm{kg}$ of IMP, EEG pattern altered into slow, high-voltage waves. Modification of EEG continued for about one hour.

3. Effects of the drugs on the conditioned reflexes.

After the stabilization of $\mathrm{DCR}$ in pigeon, $5 \mathrm{mg} / \mathrm{kg}$ of $\mathrm{CPZ}$ was injected intramuscularly. Between 16 to 60 minutes after administration CS was presented 10 times at varying intervals. DCR was fully preserved after the $\mathrm{CPZ}$-treatment. In response to CS, EEG was activated immediately, the pulse rate increased, and at the same time it moved violently.

$2 \mathrm{mg} / \mathrm{kg}$ of IMP was administered in the same way into pigeon elaborated with DCR. DCR was not destroyed by this dosage of IMP. With an additional injection of $2 \mathrm{mg} / \mathrm{kg}$ of IMP, the DCR, the conditioned changes in EEG as well as the pulse rate were not disturbed.

After the stabilization of FCR in pigeons, $2 \mathrm{mg} / \mathrm{kg}$ and $5 \mathrm{mg} / \mathrm{kg}$ of $\mathrm{CPZ}$ were administered respectively. 10 minutes after administration of $2 \mathrm{mg} / \mathrm{kg}$ of CPZ, CS evoked EEG-depression, conditioned pecking of the key and the

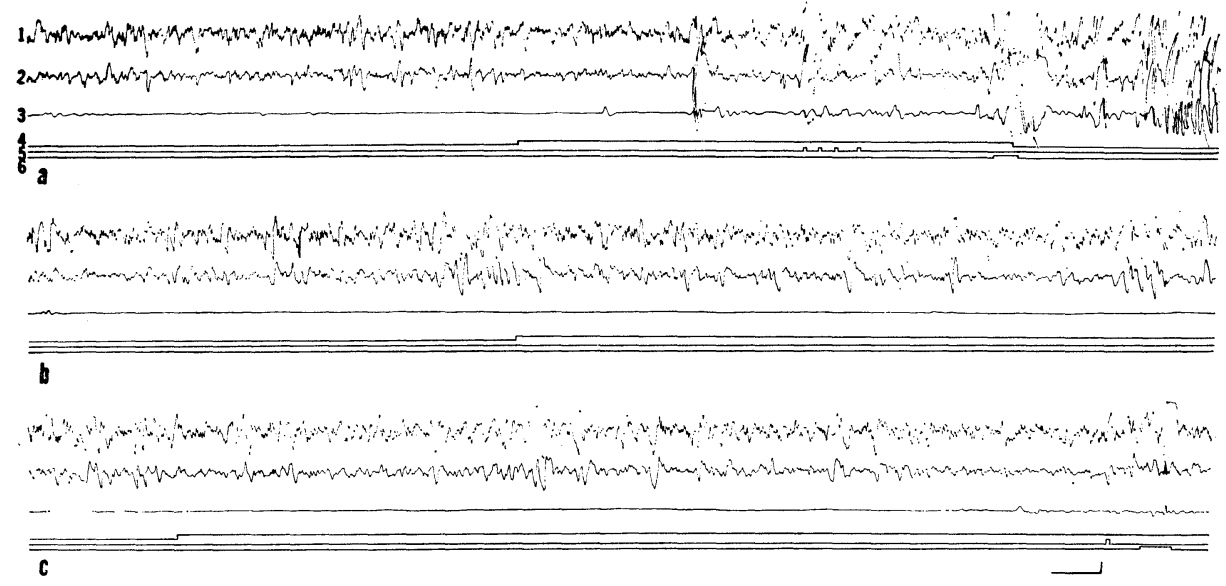

FIG. 6. Effect of $\mathrm{CPZ}$ on the food motor conditioned reflex of the pigeon. aControl tracing. b-30 minutes after administration of $\mathrm{CPZ}(5 \mathrm{mg} / \mathrm{kg})$. c-60 minutes after administration. Leads -1 : right frontal-right occipital area; 2 : right occipital area ; 3 : movement of the body; 4 : mark of CS; 5 : mark of pecking; 6 : mark of taking foods. Calibration : $100 \mu \mathrm{V}, 1$ sec. 


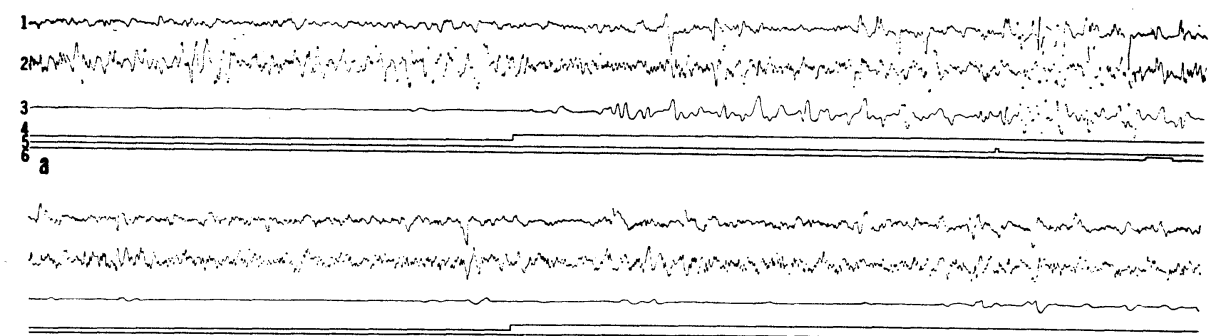

b

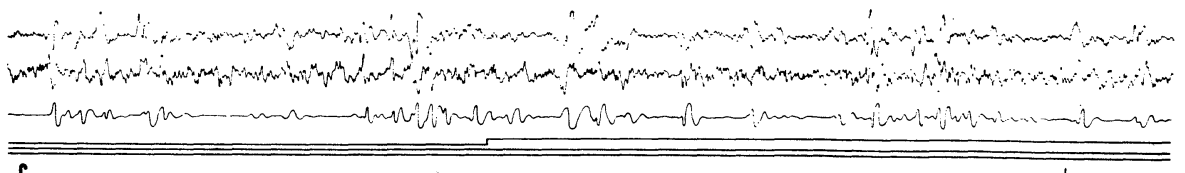

FIG. 7. Effect of IMP on the EEG and food motor conditioned reflex of the pigeon. a-Control tracing. $\mathrm{b}-30$ minutes after the administration of IMP ( $5 \mathrm{mg}$ / $\mathrm{kg})$. c-60 minutes after administration. Leads and calibration as in FIG. 6.

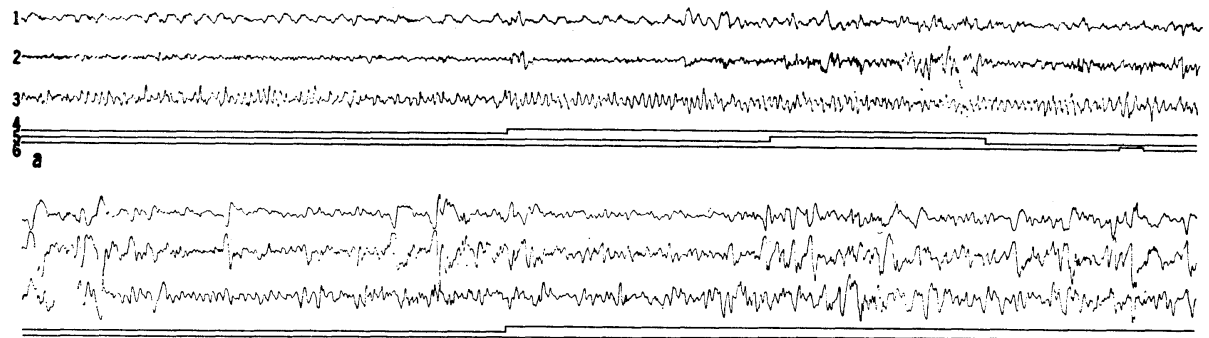

ב

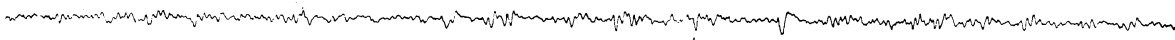

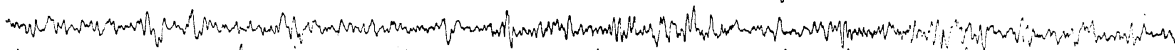

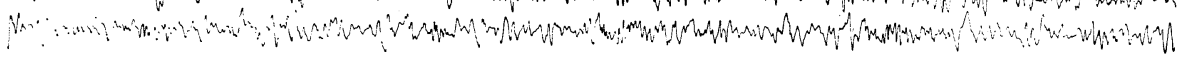

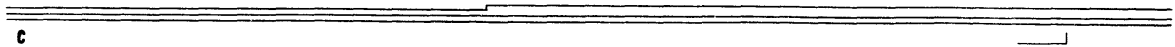

FIG. 8. Effect of $\mathrm{CPZ}$ on the EEG and food motor conditioned reflex of the rabbit. a-Control tracing. $b-20$ minutes after administration of $\mathrm{CPZ}(5 \mathrm{mg} / \mathrm{kg})$. c-1 hour after administration. Leads -1 : right frontal area; 2 : right occipital area; 3 : left parietal-left occipital area; 4 : mark of CS; 5 : mark of bar-pressing; 6 : mark of taking food. Calibration: $200 \mu \mathrm{V}, 1 \mathrm{sec}$.

taking of foods. 15 minutes later, however, EEG showed activation in response to CS, but conditioned behaviors such as walking to the feeder, pecking and so on, did not appear. With the presentation of CS 40 minutes after injection EEG slightly depressed and only 'looking above' without pecking was observed. About one hour later FCR recovered perfectly.

With $5 \mathrm{mg} / \mathrm{kg}$ of $\mathrm{CPZ}$ the pigeon rested quietly in front of the feeder. During one hour after administration, in response to CS a slight activation 


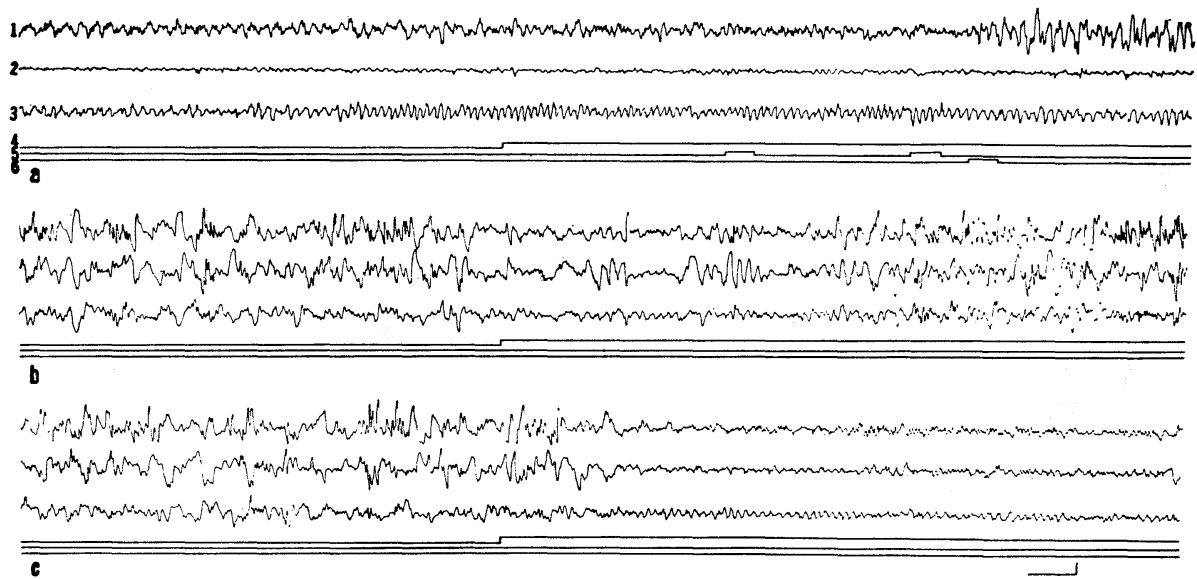

FIG. 9. Effect of IMP on the EEG and food motor conditioned reflex of the rabbit. a-Control tracing. b-20 minutes after administration of IMP $(5 \mathrm{mg} / \mathrm{kg})$. c-1 hours after administration. 35 seconds after introduction of CS the animal pressed the bar and took foods. Leads and calibration as in FIG. 8.

of EEG was observed but the conditioned behaviors were absent (FIG. 6b). In about one hour later FCR appeared again (FIG. 6c).

IMP was applied in the same manner as CPZ. After the stabilization of FCR in pigeons, $2 \mathrm{mg} / \mathrm{kg}$ and $5 \mathrm{mg} / \mathrm{kg}$ were injected respectively. Some minutes after injection of $2 \mathrm{mg} / \mathrm{kg}$ of IMP, in response to CS the pigeon only look around without performing FCR. FCR was not fully preserved for 2 hours. After this, with the presentation of CS the pigeon began to act as if pecking at the key. 30 minutes later FCR recovered.

With the injection of $5 \mathrm{mg} / \mathrm{kg}$ of IMP, the pigeon was stationary and cooing in front of the feeder. And with the presentation of CS, some minutes later, the pigeon responded only by lifting up its head while EEG did not show any noticeable changes (FIG. 7b). During 5 hours after injection FCR did not appear and EEG was not altered in response to CS (FIG. 7c). Test for FCR after 24 hours showed that it recovered perfectly.

After the stabilization of $\mathrm{FCR}$ in rabbits, $2 \mathrm{mg} / \mathrm{kg}$ and $5 \mathrm{mg} / \mathrm{kg}$ of $\mathrm{CPZ}$ and IMP were intraperitoneally injected respectively. Following the administration of $2 \mathrm{mg} / \mathrm{kg}$ of $\mathrm{CPZ}$, the EEG-tracings altered into slow, high-voltage waves, though desynchronization occasionally appeared. Therefore, distinct changes of EEG which follows CS were not ascertained for about 4 hours. Similarly, during these hours, FCR sometimes failed to respond to CS. However, after this FCR recovered and conditioned EEG appeared. With an in jection of $5 \mathrm{mg} / \mathrm{kg}$ of CPZ, EEG revealed activation for a short duration but FCR was not evoked in response to CS (FIG. 8b). This condition continued for more than 4 hours (FIG. 8c). FCR was found to recover on the following day. 
In the case of $2 \mathrm{mg} / \mathrm{kg}$ of IMP in rabbits, soon after injection EEG did not undergo changes and FCR was not performed with the introduction of CS. More than 10 minutes after injection, in response to CS the EEG showed activation but FCR was not elicited. However, nearly 50 minutes after injection conditioned EEG as well as FCR appeared. With the administration of $5 \mathrm{mg} / \mathrm{kg}$ of IMP, 13 minutes after injection no conditioned response on EEG and in behavior were observed following the introduction of CS. More than half an hour after injection, in response to CS desynchronization of EEG occurred but no conditioned reflex was elicited (FIG. 9b). Finally, after about one hour, CS evoked both EEG-depression and FCR, which took a long latency to press the bar and to take food (FIG. 9c). After this FCR recovered perfectly.

\section{DISCUSSION}

The comparative studies of the effects of $\mathrm{CPZ}$ and IMP in phylogenetically different kinds of vertebrates must be instructive, to a certain extent, in elucidating the mechanism of the action towards these drugs. As is known investigations on the drugs under consideration from the point of view of phylogeny may not be abundant, but the works of BARUK et al. (1955) and IVANOVA (1961), in particular, attention should be paid to this respect.

As it has been generally accepted that CPZ brings about a sedative effect in mammals, in the lower vertebrates our observation on the effects of CPZ, also indicates that it acts in a similar manner. However, it is interesting to note that a postulation was established that $\mathrm{CPZ}$ acts more strongly upon animals in which the neocortex is developed than those which has no neocortex. Administration of $5 \mathrm{mg} / \mathrm{kg}$ of $\mathrm{CPZ}$ in mice, rats and rabbits is enough to cause the sedative state where spontaneous activity decreases and flaccidity results, as in cat, dog, monkey and so on. On the other hand, in lower vertebrates without neocortex, the same dose of $\mathrm{CPZ}$ would not produce any observable behavioral changes, but the influence of the drug begins to appear only with doses of $25 \mathrm{mg} / \mathrm{kg}$ and over.

Observation on EEG in the CPZ-treated pigeons and rabbits seems to coincide with the above finding. EEG pattern in both kinds of the animals alters into slow, high-voltage waves after administration of $5 \mathrm{mg} / \mathrm{kg}$. In rabbits the modified EEG-tracing will remain unchanged following external stimuli, as is found by LONGO (1962) in the same animal and by BRADLEY \& HANCE (1957) in cat. On the other hand, in response to external stimuli desynchronization appears in treated pigeons.

According to our experiment dealing with the influence of the drug on the conditioned reflex activity, $5 \mathrm{mg} / \mathrm{kg}$ of $\mathrm{CPZ}$ did not impair the simple defensive $C R$ in pigeons. A large number of work has been made on several 
kinds of mammals to observe the effect of $\mathrm{CPZ}$ on the conditioned behavior. A series of experiments made by Courvolsier et al. (1953), GATTI \& Frank (1961), KEY (1961) and others using different defensive CR in rats showed that CPZ impairs CR even in small doses. SIGG (1959) discovered also in rats that the conditioned escape-avoidance reflex is profoundly damaged by $3 \mathrm{mg} /$ $\mathrm{kg}$ and totally blocked by $10 \mathrm{mg} / \mathrm{kg}$ of $\mathrm{CPZ}$. Although there may exist differences in complexity of the defensive conditioned reflex method employed by the investigators, CPZ seems to affect stronger on the defensive CR of the neocorticate animals than that of the non-neocorticate ones.

However, it is noteworthy that $5 \mathrm{mg} / \mathrm{kg}$ of $\mathrm{CPZ}$ either in pigeons or rabbits disturbs the performance of FCR, but the degree of the disturbance is more prominent in rabbits than pigeons. The result of BLOUGH (1957) with pigeon using a modification of the Skinner's operant conditioning method indicates that $\mathrm{CPZ}$, though with higher doses than ours, disturbs the FCR. Similarly, IVANOVA (1961) observed that in fish, pigeons as well as rabbits food-getting $\mathrm{CR}$ is abolished following the administration of CPZ. These results seem to show that $\mathrm{CPZ}$ gives an influence upon the neural mechanism of temporary connections, and that the more complex the conditioned behavior the more pronounced is the disturbance. Because it may be considered that the food-getting or lever-pressing $C R$ is a more complicated multiple-chain reflex which belongs to the so-called instrumental CR. ASTRUP (1965) supposes that a conditioned climbing to avoid shock in rats which is one type of instrumental conditioning is inhibited by the action of $\mathrm{CPZ}$ whereas the unconditioned reflexes are not disturbed, while in classical conditioning it has more effect upon the unconditioned than upon the conditioned reflex. Although his hypothesis has not been ascertained from our present study, it may be understandable from the fact that the mode of action of $\mathrm{CPZ}$ on the reticular formation that is responsible for the temporary connection is multifarious as will be discussed later.

It is generally considered that the action of IMP upon the organisms is much more complicated when compared with that of CPZ. So this might be the reason for the long history of reserches before IMP was recognized as a psycho-analeptic drug. In our present study it was found that IMP acts in a manner in which the lower the animals in phylogeny the more profound is its effect. As a rule, for IMP stronger effects are observed in the non-neocorticate vertebrates than in the neocorticate ones. Accordingly, there is a reverse relationship between $\mathrm{CPZ}$ and IMP in their effect.

In the animals experimented including lower mammals, IMP even in small doses produces impediments in behavior at varying way; for instance, inactivity in some and excitatory state in the others, being different with respective animals. In particular, the sedative effect is obvious in lower mammals. However, SIGG (1959) describes that smaller doses of IMP $(1-5 \mathrm{mg} / \mathrm{kg})$ do not 
induce an increase of psychomotor activity (dog, cat, rat, mouse), while larger doses $(5-10 \mathrm{mg} / \mathrm{kg})$ produce sedative state in cats and dogs. He may suggest that the sedative effect to be induced depends upon the dosage administered. On the contrary, in higher mammals, especially in primates, BARUK \& LAUNAY (1961) observed that IMP acts towards excitatory direction as psycho-analetique as used in therapy in the human patients. Thus, these facts may reflect the manifoldness of the action of IMP on the central nervous system. Therefore, it would not tell a whole story that IMP acts merely as psycho-analetique upon the central nervous system in higher mammals. Comparative study of IMP seems to indicate that it acts upon the lower centers rather than the higher centers.

Comparison of the actions between $\mathrm{CPZ}$ and IMP reveals an interesting finding on the EEG. EEG pattern of the CPZ-treated pigeons shows slow, high-voltage waves, while that of the IMP-treated is fast, low-voltage waves. On the other hand, in rabbits, of either CPZ- or IMP-treatment, EEG picture is altered to synchronizing pattern as well. As is stated above, with IMP the cerebral electrical activity behaves differently between the non-neocorticate and the neocorticate animals. In other words, according to the classification of Bovet et al. (1957), CPZ is synchronisant and IMP is desynchronisant in pigeon, but both CPZ and IMP are synchronisant in rabbit. However, the reason why IMP acts upon the central nervous system differently in phylogenetically different series of animals is not clear, but it will be discussed in connection with the reticular formations later.

HIMwich (1959) reported in rabbits that IMP blocks the EEG arousal reaction to painful stimuli as well as his case of CPZ-treatment. On the contrary, our result with the same animal shows that IMP, unlike CPZ, does not prevent the appearance of desynchronization in response to external stimuli despite being in sedative state.

Furthermore, as to the effect of IMP on the conditioned reflexes in pigeons, the simple defensive $\mathrm{CR}$ is not destroyed or slightly attenuated following the administration of $2-5 \mathrm{mg} / \mathrm{kg}$ of the drug, while FCR is severely impaired by the same dosage. However, FCR in rabbits following the administration of $5 \mathrm{mg} / \mathrm{kg}$ of IMP is only slightly impaired for a relatively short period. Results concerning the effect of IMP on the conditioned reflexes seem to be diverse among the investigators. SIGG (1959) describes that IMP has no influence upon the conditioned avoidance reflex in rats even with large doses. On the other hand, many other investigators appear to be in agreement that IMP impairs the avoidance conditioned reflex although the degree of its impairment varies according to the respective investigators: HANSON (1961) in rat and monkey; VERNIER et al. (1962) ; MAXWELL \& PALMER (1961). Recently, KOBAYASHI \& SUZUKI (1966) found that intraventricular injection of IMP in a small dose attenuates the avoidance conditioned reflex while intraperitoneal 
injection of IMP did not cause any damage, but CPZ with the latter method of administration caused disturbances. They stressed that it is of utmost importance to determine the actual effects and methods of administration of those tranquilizing drugs. Furthermore they consider that IMP may have stronger influence upon the cortex than $\mathrm{CPZ}$, which is more effective in the periventricular areas. However, their conclusion may not be valid because the effect of IMP is more profound than that of $\mathrm{CPZ}$ in the non-neocorticate animals.

Although the result of our present investigation would not contribute to the solution of the question as the site of action of either CPZ or IMP in the central nervous system, in lower vertebrates as well as in higher animals the reticular formation is the one which is most responsible to these drugs. Many writers describe the influence of the reticular formation produced by CPZ. LONGO et al. (1954) state that CPZ depresses the effect of reticular formation. ANOKHIN (1956) describes the blocking action on the rostral area of the reticular formation. Speaking more definitely, BRADLEY \& KEY (1958) suggested that $\mathrm{CPZ}$ blocks the synapse between the collaterals of the lemniscus system and the reticular formation. At present, it may be generally accepted that administration of $\mathrm{CPZ}$ produces a depression of the EEG arousal response. Discussing this problem in relation to the phylogeny of the function of the reticular formations is undoubtedly useful.

In lower vertebrates neurons of the brain stem reticular formations are widely dispersed in the sensory and motor zone (TUGE, 1932; TUGE et al., 1966). Reticular formations have developed to constitute complicated relay stations in order to correlate the function of somatic and visceral components and then possibly to establish the descending excitatory and inhibitory function. Later, ascending diffuse activating system developed particularly in the neocorticate animals. Accordingly, it may be considered that if CPZ inhibits the activity of reticular formations, in lower vertebrates the function of correlation between somatic and visceral components will be impaired first, as is revealed in the behavioral changes in the CPZ-treated animals.

VAN METER et al. (1959) found that IMP in low doses blocks the reticular formation producing the synchronized EEG pattern and preventing EEG arousal response as in the action of CPZ. Though various sites of the central nervous system may be influenced by the administration of IMP, it is also believed by certain investigators that the reticular formation is the one which has a specific effect of IMP. It seems reasonable to consider that IMP that has a similar chemical structure with $\mathrm{CPZ}$ acts specifically upon the reticular formation. At the same time, it is logically understandable that mode of action is different between $\mathrm{CPZ}$ and IMP in influencing the brain stem reticular formations. Difference between the actions of CPZ and IMP is to be found in their different, though similar, chemical structure and in 
the site of their action within the reticular formations. That IMP acts vigorously upon the reticular formations in lower vertebrates appears to be related with the impairment of the primary function of the reticular formation, e.g., the functions correlating between the somatic and visceral components, and with the less influence on the non-specific activating system which developed later in phylogeny. CPZ may be related with the reverse relationship, on the other hand. At any rate, the influence of these drugs upon the reticular formations largely depends upon the quantity of the drugs employed. In particular, contradiction between EEG picture and behavior which is found frequently in experiments employing these drugs may be due to that as explained above. In this connection, it may be of some interest to note that LEvTova \& SLEZIN (1968) found that CPZ blocks emotional reactions but IMP stimulates them in cat.

\section{SUMMARY}

1. Effect of chlorpromazine (CPZ) and imipramine (IMP) on the overt behavior was studied in fish, frogs, pigeons, mice, rats, and rabbits and also on the EEG and conditioned reflex activity in pigeons and rabbits.

2. In general, it can be said that IMP acts more strongly upon the nonneocorticate animals in their behavioral changes than the neocorticate ones, while for $\mathrm{CPZ}$ the reverse manner is true.

3. In pigeons the administration of $\mathrm{CPZ}$ alters, to some degree, the EEG pattern of slow, high-voltage wave, while that of IMP provokes EEG-desynchronization. In rabbits the administration of $\mathrm{CPZ}$ as well as IMP modifies the EEG pattern into slow, high-voltage wave. Observations on the duration of the effect on EEG changes show that CPZ is much stronger than IMP in mammals.

4. In pigeons the administration of $\mathrm{CPZ}$ does not disturb simple defensive conditioned reflex, but food motor conditioned reflex is impaired. Administration of IMP impairs more profoundly simple defensive conditioned reflex and food motor conditioned reflex than that of $\mathrm{CPZ}$ in pigeons. In rabbits food motor conditioned reflex is very slightly disturbed by low doses of IMP, only being disappeared by high doses of the drug, while low doses of CPZ are enough to cause the disappearance of food motor conditioned reflex.

5. Discussion is made by comparing the action of both drugs, from the point of view of phylogeny on the central nervous system, and suggests that although the action of IMP is complex, it acts primarily upon the function of correlation between the somatic and visceral components in the brain stem reticular formations and then the diffuse activating system; the effect of $\mathrm{CPZ}$, on the other hand, is primarily on the activating system, the descending i nhibitory function and the neocortex, while affecting the function of correla- 
tion between the somatic and visceral components of the reticular formations.

This work was supported in part by a grant from the Ministry of Education of Japan, awarded to 'Research Group of Comparative Neurochemistry' organized by Prof. Yasuzo TsukAda, Medical College, Keio University. A part of the paper was read before the Third National Conference of Bulgarian Society for Physiological Sciences, Varna, May 29-31, 1967. Acknowledgement is due to Dr. Y. KANAYAma and Mr. S. OCHIAI for their kind assistance throughout the experiment.

\section{REFERENCES}

1) Anokhin, P.K. The role of the reticular formation of the brain stem in transmission of unconditioned excitation to cerebral cortex. Communications at the XIX International Congress of Physiologists in Bruxelles. Pub. USSR Academy of Sciences. 142-150, 1956.

2) Astruy, C. Pavlovian Psychiatry: A New Synthesis. Charles C. Thomas Publisher, Springfield, Ill. 1965.

3) Barup, H. and Launay, J. La loi des stades et la psychopharmacologie expérimentale chez le singe. Neuro-psychopharmacology, vol. 2 (Ed. by E. Rothlin). Elsevier Pub. 222-225, 1961.

4) Baruk, H., Launay, J. et Berges, J. La catatonie expérimentale par la chlorpromazine (présentation d'un film). Ann. Méd. Psychol., 113, 1, no. 439-442, 1955.

5) Blough, D.S. Some effects of drugs on visual discrimination in the pigeon. Ann. New York Academy of Sciences. 733-739, 1957.

6) Bovet, D., Longo, G. Et Silvestrini, B. Les méthodes d'investigations electrophysiologiques dans l'étude des médicaments tranquillisants. Contribution à la pharmacologie de la substance réticulaire. Symp. Intern. sur médicaments psychotropes, Milan. In Psychotropic drugs (Pub. by Elsevier), 193-206, 1957.

7) Bradley, P.B. And HANCE, A.J. The effect of chlorpromazine on the electrical activity of the cerebral cortex in a chronic cat preparation. EEG Clin. Neurophysiol., 9: 194, 1957.

8) Bradley, P.B. And Key, B.J. The effect of drugs on arousal responses produced by electrical stimulation of the reticular formation of the brain. EEG Clin. Neurophysiol., 10 : 97-110, 1958.

9) Courvoisier, S., Fournel, J., Ducrot, R., Kolsky, M. And Koetschet, P. Proprietes pharmacodynamiques du chlorhydrate de chloro-3-(dimethylamino-3propyl)-10-phenothiazine (4560 RP). Arch. intern. pharmacodynam., 92 : 305-361, 1953.

10) Gatti, G.L. And Frank, M. The technique of the "pole climbing response". Effect of various drugs on the latency-period and flight reaction of the rat. Neuropsychopharmacology, vol. 2 (Ed. by E. Rothlin). Elsevier Pub. 147-150, 1961.

11) Hanson, H.M. The effects of amitriptyline, imipramine, chlorpromazine and nialamide on avoidance behavior. Fed. Proc., $20: 396,1961$.

12) Hiebel, G., Bonvallet, M. et Dell, P. Action de la chlorpromazine (Largactil, $4560 \mathrm{RP}$ ) an niveau du système nerveux central. Sem. des Hôsp. Paris, 30 : no. 37, 2346-2353, 1954.

13) Himwich, H.E. Cited from Van Meter, W.G., Owens, H.F. and Himwich, H.E., 1959.

14) Ivanova, V.I. The mechanism of the action of chlorpromazine on alimentary motor conditioned reflexes in fishes, pigeons and rabbits. J. High. Nerv. Act., 11 : 1120-1126, 1961 (in Russian). 
15) KEY, B.J. The effect of chlorpromazine and LSD on conditioned avoidance responses. Neuro-psychopharmacology, vol. 2 (Ed. by E. Rothlin). Elsevier Pub. 147-150, 1961.

16) Kobayashi, T. And Suzuki, J. Effects of psychotropic drugs on behavior and EEG, following direct administration to dog's brain. Folia. Psychiat. Neurol. Jap., 20 : 151-165, 1966.

17) Levtova, F.A. And Slezin, V.B. Effect of chlorpromazine and tofranil on behavioral reactions of cats to electrical stimulation of the subcortical brain formations. J. High. Nerv. Act., $18: 272-279,1968$ (in Russian).

18) Longo, V.G. Electroencephalographic atlas for pharmacological research. Effect of drugs on the electrical activity of the rabbit brain. Elsevier Pub. New York, 1962.

19) Longo, V.G., Von Berger, G.P. And Bovet, D. Action of nicotine and of the 'Ganglioplegiques centraux' on the electrical activity of the rabbit brain. $J$. Pharmacol., 111 : 349-359, 1954.

20) Maxwell, D.R. And Palmer, H.T. Demonstration of anti-depressant or stimulant properties of imipramine in experimental animals. Nature, 191: 84, 1961.

21) Sigg, E.B. Pharmacological studies with tofranil. Canad. Psychiat. Ass. J., 4 : Suppl., 75-83, 1959.

22) Tuge, H. Somatic motor mechanisms in the midbrain and medulla oblongata of Chrysemys elegans (Wied). J. Comp. Neur., 55: 185-271, 1932.

23) Tuge, H., Chang, H.Y., Kanayama, Y. And Horikiri, N. Functional analysis of the brain stem reticular formation by means of motor conditioned reflexes. Abhandl. d. Deutsch. Akad. d. Wissen. z. Berlin. Kl. f. Med., Nr. 2, 89-93, 1966.

24) Van Meter, W.G., Owens, H.F. and Himwich, H.E. Effects of tofranil, and antidepressant drugs, on electrical potentials of rabbit brain. Canad. psychiat. Ass. J., 4 : Suppl., 113-119, 1959.

25) Vernier, V.G., Hanson, H.M. and Stone, C.A. The pharmacodynamics of amitriptyline. In Psychosomatic Medicine. First Hahnemann Symp. (Ed. by Nodine, J.H. and Moyer, J.H.). Lea \& Febigar Pub. Philadelphia, 683-690, 1962. 